\title{
ACÚMULO DE FITOMASSA DO MILHO APÓS O ESPIGAMENTO EM FUNÇÃO DO PARCELAMENTO DA COBERTURA NITROGENADA
}

\author{
LUÍS SANGOI ${ }^{1}$,FERNANDO PANISON ${ }^{1}$, MURILO MIGUEL DURLI', \\ LUCIELI SANTINI LEOLATO ${ }^{1}$, ANTONIO EDUARDO COELHO ${ }^{1}$, \\ HUGO FRANÇOIS KUNESKI ${ }^{1}$ e VANDER DE LIZ OLIVEIRA'
}

\author{
${ }^{1}$ Universidade do Estado de Santa Catarina - UDESC/Centro de Ciências Agroveterinárias \\ Av. Luís de Camões, 2090 - Conta Dinheiro, Lages-SC/CEP 88520-000 \\ luis.sangoi@udesc.br,fernandopanison@hotmail.com,murilodurli@gmail.com,lucieli.leolato@gmail.com, \\ coelhoagro7@gmail.com,hugokuneski@outlook.com,vanderdlo@hotmail.com
}

Revista Brasileira de Milho e Sorgo, v.18, n.1, p. 61-73, 2019

\begin{abstract}
RESUMO - O fracionamento da adubação nitrogenada é uma estratégia que pode aumentar o acúmulo de massa nos grãos do milho. Este trabalho objetivou avaliar os efeitos do parcelamento da cobertura nitrogenada sobre o acúmulo de fitomassa nas folhas, colmos e grãos após o espigamento do milho. O experimento foi implantado em Lages-SC. Foram testados dois híbridos (P30F53YH e P1680YH) e seis sistemas de aplicação do nitrogênio: testemunha sem $\mathrm{N}$, todo $\mathrm{N}$ aplicado em V5, V10 ou VT (pendoamento), 1/2 N em V5 + 1/2 N em V10, 1/3 N em V5 + 1/3 N em V10 + $1 / 3 \mathrm{~N}$ em VT. A dose de $\mathrm{N}$ foi de $300 \mathrm{~kg} \mathrm{ha}^{-1}$. Avaliou-se o acúmulo de fitomassa aos 0, 14, 28, 42, 56 e 70 dias após o espigamento. A massa seca dos grãos dos dois híbridos aumentou linearmente em todos os sistemas testados. As maiores taxas de incremento (2,4 a 2,7 $\left.\mathrm{g} \mathrm{dia}^{-1}\right)$ foram obtidas com a aplicação integral de $\mathrm{N}$ em V5 e as menores (1,5 a 1,6 $\left.\mathrm{g} \mathrm{dia}^{-1}\right)$ na testemunha. $\mathrm{O}$ fracionamento da adubação nitrogenada de cobertura em três estádios fenológicos não aumentou a massa dos grãos, em relação à fertilização feita integralmente em V5 ou V10.
\end{abstract}

Palavras-chave: Zea mays, enchimento de grãos, cultivares, fenologia, nitrogênio.

\section{MAIZE DRY MASS ACCUMULATION AFTER SILKING AS AFFECTED BY THE SPLITTING OF NITROGEN SIDE-DRESS FERTILIZATION}

\begin{abstract}
ABSTRAT- The splitting of nitrogen fertilization is a strategy that can increase kernel dry mass accumulation of maize. This work was carried out aiming to evaluate the effects of splitting nitrogen side-dress fertilization on leaf, stem and grain dry mass accumulation after maize silking. The experiment was set in Lages, SC, South of Brazil. Two hybrids (P30F53YH and P1680YH) and six nitrogen fertilization systems were tested: control without $\mathrm{N}$, all $\mathrm{N}$ side-dressed at V5, V10 or VT (tasseling), $1 / 2 \mathrm{~N}$ at V5 $+1 / 2 \mathrm{~N}$ at V10, $1 / 3 \mathrm{~N}$ at V5 $+1 / 3 \mathrm{~N}$ at V10 $+1 / 3 \mathrm{~N}$ at VT. Nitrogen rate was 300 $\mathrm{kg} \mathrm{ha}^{-1}$. Dry mass accumulation was determined at $0,14,28,42,56$ and 70 days after silking. The kernel dry mass of both hybrids increased linearly at all six $\mathrm{N}$ fertilization systems. The highest increment rates $\left(2.4\right.$ to $\left.2.7 \mathrm{~g} \mathrm{day}^{-1}\right)$ were achieved when all $\mathrm{N}$ was side-dressed at V5. The lowest rates $\left(1.5\right.$ to $\left.1.6 \mathrm{~g} \mathrm{day}^{-1}\right)$ were registered in the control. The splitting of nitrogen side-dress fertilization in three growth stages did not increase kernel dry mass, when compared to the fertilization carried out entirely at V5 or V10.
\end{abstract}

Keywords: Zea mays, grain filling, hybrids, phenology, nitrogen. 
A cultura do milho passou por importantes avanços tecnológicos nos últimos anos, destacandose o melhoramento genético com o desenvolvimento de híbridos mais precoces e produtivos. Estas mudanças levaram ao aumento da quantidade de nitrogênio aplicada na lavoura e à necessidade de maior parcelamento das fertilizações nitrogenadas (Sangoi et al., 2016).

A construção do aparato fotossintético do milho está praticamente completa no florescimento, sendo pouco incrementada após esse período. Isto se deve ao hábito determinado de crescimento da cultura e ao fato de a planta começar a priorizar após o espigamento o desenvolvimento das partes reprodutivas, mobilizando os fotoassimilados das folhas para os grãos (Ciampitti \& Vyn, 2013). A acumulação de massa seca nas diferentes partes da planta possui um padrão semelhante no tempo. Ela apresenta acentuado acréscimo no florescimento e início do enchimento de grãos, principalmente em lavouras de altos rendimentos (Kosgey et al., 2013).

Estudos envolvendo o comportamento da absorção do nitrogênio entre híbridos antigos e atuais identificaram resultados importantes que auxiliam no manejo do nutriente. Os híbridos modernos absorvem nitrogênio em quantidades significativas após o florescimento (Bruin \& Butzen, 2014; Ning et al., 2014). A remobilização do nitrogênio das folhas e dos colmos para o enchimento de grãos é limitada. Portanto, é necessário garantir nitrogênio disponível para a absorção durante todo o ciclo da cultura, inclusive após o espigamento, para que não ocorram deficiências que reduzam a produtividade (Ciampitti \& Vyn, 2013).

Além do alto potencial produtivo, outro aspecto importante é a precocidade dos híbridos disponíveis. Quanto mais precoce for o híbrido, menor é o período de absorção de nitrogênio e maior a resposta potencial ao parcelamento da fertilização nitrogenada (Sangoi et al., 2016). O milho após o florescimento pode apresentar índices de absorção de até 50\%, indicando que a aplicação tardia de parte do $\mathrm{N}$ pode trazer vantagens (Bruin \& Butzen, 2014). Entre estas, pode ser citada a manutenção da área foliar por um período maior de tempo durante o enchimento de grãos, aumentando a atividade fotossintética da cultura e, consequentemente, o rendimento de grãos (Debruin et al., 2013).

A redução da senescência foliar na cultura do milho é positiva, pois ele apresenta alto potencial de utilização da radiação solar, convertendo o carbono mineral em carbono orgânico, fomentando o acúmulo de fotoassimilados nos grãos e, consequentemente, aumentando a produtividade (Argenta et al., 2003). Trabalhos conduzidos por Tollenaar e Lee (2002) e Sangoi et al. (2013) demonstraram que há diferenças na senescência foliar entre os híbridos atuais quando comparados aos mais antigos. Com o decorrer dos anos ocorreu um acréscimo no tempo da permanência de folhas verdes na planta de milho. Isto indica que a característica denominada popularmente de "stay green" é hereditária. Assim, os híbridos atuais apresentam maiores produtividades por possuírem menor taxa de senescência foliar. Ao retardarem a senescência, eles passam a interceptar mais radiação solar e acumular maior quantidade de massa seca nos grãos (Duvick, 2005; Echarte et al., 2008). O fornecimento de nitrogênio na época adequada ao longo do ciclo da cultura pode potencializar esta característica.

O estudo da taxa de absorção de nutrientes e do acúmulo de massa seca em função dos estádios fenológicos da cultura serve como subsídio para definir a época mais indicada para realizar a adubação nitrogenada de cobertura. Isto contribui para o aumento da eficiência na lavoura pela melhor utilização dos 
insumos e do solo, diminuindo custos e aumentando o rendimento.

Este trabalho foi conduzido com base na hipótese de que o maior fracionamento da adubação nitrogenada, com a aplicação de uma parte da dose no florescimento da cultura, é uma estratégia que prolonga a duração da área foliar e aumenta a massa acumulada nos grãos. $\mathrm{O}$ objetivo do experimento foi avaliar o efeito do parcelamento da cobertura nitrogenada sobre o acúmulo de massa seca nas folhas, colmos e grãos após o espigamento de híbridos de milho.

\section{Material e Métodos}

O experimento foi conduzido no município de Lages, localizado no Planalto Sul de Santa Catarina, nos anos agrícolas de 2014/15 e 2015/16. As coordenadas geográficas da área experimental são $27^{\circ} 50^{\prime} 35^{\prime}$ " de latitude Sul, $50^{\circ} 02^{\prime} 45^{\prime}$ ' de longitude oeste e altitude de 849 metros. De acordo com a classificação de Köppen, o clima da região é do tipo $\mathrm{Cfb}$, mesotérmico, com verões brandos, temperaturas médias do mês mais quente inferiores a $22{ }^{\circ} \mathrm{C}$ e precipitações pluviais bem distribuídas. O solo é classificado como Nitossolo Vermelho Distrófico típico. Ele apresentava, em setembro de $2014,480 \mathrm{~g} \mathrm{~kg}^{-1}$ de argila e $52 \mathrm{~g}$ $\mathrm{kg}^{-1}$ de matéria orgânica.

O delineamento experimental utilizado foi de blocos ao acaso dispostos em parcelas sub-divididas com três repetições por tratamento. Na parcela principal foram avaliados dois híbridos de milho: P1680YH, de ciclo hiperprecoce, e P30F53YH, de ciclo precoce. A soma térmica para conclusão do ciclo dos dois híbridos é de 1.220 e 1.556 graus-dia, respectivamente. Nas subparcelas foram testados seis sistemas com diferentes épocas e parcelamentos da aplicação do fertilizante nitrogenado em cobertura: testemunha sem $\mathrm{N}$, todo $\mathrm{N}$ aplicado em V5 (cinco folhas expandidas), todo o N aplicado em V10 (dez folhas expandidas), $1 / 2$ do $\mathrm{N}$ em V5 e $1 / 2$ em V10, 1/3 em V5, 1/3 em V10 e 1/3 em VT (pendoamento) e todo N em VT, de acordo com a escala proposta por Ritchie et al. (1993). Cada subparcela foi constituída por seis linhas, espaçadas em $70 \mathrm{~cm}$, com $7 \mathrm{~m}$ de comprimento. A segunda e a terceira linhas foram utilizadas para as avaliações, perfazendo uma área útil de $8,4 \mathrm{~m}^{2}$.

A área experimental recebeu adubação com a mistura de fósforo, potássio e nitrogênio no dia da semeadura, levando em consideração resultados da análise de solo realizada anualmente no mês de setembro antes da instalação do experimento e seguindo as recomendações da Comissão de Química e Fertilidade do Solo-RS/SC (2004) para alcançar tetos produtivos de $21 \mathrm{t} \mathrm{ha}^{-1}$ de grãos. As fontes utilizadas de N, P e K foram ureia ( $45 \%$ de $\mathrm{N})$, superfosfato triplo (46\% de $\mathrm{P} 2 \mathrm{O} 5)$ e cloreto de potássio ( $60 \%$ de K2O), respectivamente. As doses aplicadas na semeadura foram de $30 \mathrm{~kg} \mathrm{ha}^{-1}$ de N, $295 \mathrm{~kg} \mathrm{ha}^{-1}$ de $\mathrm{P}_{2} \mathrm{O}_{5}$ e $170 \mathrm{~kg} \mathrm{ha}^{-1}$ de $\mathrm{K}_{2} \mathrm{O}$. Os fertilizantes foram distribuídos superficialmente próximos às linhas de semeadura. A adubação de cobertura com nitrogênio foi feita de acordo com o estádio fenológico previsto em cada tratamento. A dose de $\mathrm{N}$ aplicada em cobertura foi de $300 \mathrm{~kg} \mathrm{ha}^{-1}$, tendo como fonte a ureia.

O experimento foi implantado nos dias 22 de outubro de 2014 e 15 de outubro de 2015, em sistema de semeadura direta, utilizando-se semeadoras manuais. Foram depositadas três sementes por cova para garantir o estande desejado. Quando as plantas se encontravam com três folhas expandidas, efetuouse o desbaste para ajustar a população ao valor desejado (90.000 $\left.\mathrm{pl} \mathrm{ha}^{-1}\right)$. O controle de plantas daninhas foi efetuado com duas aplicações de herbicida. A primeira foi feita logo após a semeadura, em pré-e- 
mergência das plantas daninhas, com uma mistura de atrazina e s-metolaclor $\left(1.250+1.250 \mathrm{~g} \mathrm{ha}^{-1}\right.$ de i.a. $)$. A segunda aplicação foi realizada em pós-emergência quando as plantas de milho estavam no estádio V4, utilizando o produto tembotriona (100 $\mathrm{g} \mathrm{ha}^{-1} \mathrm{de}$ i.a.). Pragas e doenças foram controladas sempre que necessário para que não interferissem no desenvolvimento das plantas. $\mathrm{O}$ ensaio foi irrigado sempre que o teor de umidade no solo foi inferior a $-0,4 \mathrm{Mpa}$, visando manter a umidade do solo próxima da capacidade de campo para otimizar a absorção do fertilizante nitrogenado.

A avaliação do acúmulo de massa seca nas diferentes partes da planta foi feita em R1 (espigamento) e 14, 28, 42, 56 e 70 dias após o espigamento. Foram colhidas em cada avaliação três plantas em sequência por subparcela. As plantas foram dissecadas, separando-se as folhas, colmos e grãos em sacos distintos, os quais foram colocados em estufa a $65^{\circ} \mathrm{C}$ até obtenção de massa constante para estimar o acúmulo de massa seca. A massa seca alocada a cada uma das partes da planta foi estimada através da média das três plantas coletadas.

Quando a cultura atingiu o estádio V4, foram marcadas em cada subparcela cinco plantas que se apresentavam uniformes fenológica e morfologicamente. Estas plantas foram utilizadas para análise da área foliar. A área foliar foi obtida medindo-se o comprimento $(\mathrm{C})$ e a maior largura $(\mathrm{L})$ de todas as folhas fotossinteticamente ativas. Foram feitas determinações de área foliar em R1 e 14, 28, 42, 56 e 70 dias após o espigamento. Consideraram-se fotossinteticamente ativas as folhas com mais de $50 \%$ de sua área verde, de acordo com critério proposto por Borrás et al. (2003) e adotado por Leolato et al. (2017). A área foliar por planta foi estimada utilizando-se a fórmula: $\mathrm{A}=\mathrm{C} \times \mathrm{L} \times 0,75$, onde o valor 0,75 é um coeficiente de correção, uma vez que as folhas não apresentam área retangular.

Os dados obtidos foram submetidos à análise de variância utilizando-se o teste F. Os valores de F foram considerados significativos ao nível de significância de 5\% $(\mathrm{P}<0,05)$. Quando alcançada significância estatística, efetuou-se também uma análise de regressão para avaliar a evolução do acúmulo de fitomassa em cada estrutura da planta. Esta análise foi feita individualmente por híbrido, testando-se os modelos linear e quadrático. Adotou-se o delineamento de parcelas subdivididas, onde a época de aplicação do fertilizante nitrogenado foi locada na parcela principal e a época de amostragem na subparcela.

\section{Resultados e Discussão}

Não houve efeito significativo da época de aplicação do fertilizante nitrogenado em cobertura sobre o acúmulo de massa seca no colmo do híbrido P30F53YH na safra 2014/15 (Figura 1A). Já para o híbrido P1680, houve diferenças significativas para os estádios em que o nitrogênio foi aplicado numa única dose quando as plantas se encontravam em V5 e V10 (Figura 1B). Nestes tratamentos detectaram-se incrementos de 0,32 e $0,38 \mathrm{~g} \mathrm{pl}^{-1}$, respectivamente, para cada dia após o estádio R1. Na safra 2015/16, o acúmulo de massa seca no colmo após o espigamento apresentou incremento linear para o híbrido P30F53YH quando o nitrogênio foi parcelado nos estádios V5-V10, aumentando $0,6 \mathrm{~g} \mathrm{pl}^{-1}$ para cada dia após R1 (Figura 1C). O híbrido P1680YH apresentou significância para o mesmo tratamento, havendo um comportamento quadrático em que ele atingiu o máximo acúmulo de massa seca aos 55 dias após o estádio R1 (Figura 1D). 
De uma maneira geral, os maiores valores absolutos de massa seca do colmo foram obtidos nas últimas amostragens realizadas aos 56 e 70 dias após o espigamento, momento em que os grãos se aproximavam da maturidade fisiológica. Resultados semelhantes foram encontrados por Borges (2006), que constatou incremento da massa do colmo até próximo à maturação fisiológica. Por outro lado, Vasconcellos et al. (1983) verificaram que os híbridos utilizados atingiram o máximo acúmulo de massa seca de colmo próximo ao florescimento.

As diferenças no momento em que o colmo atinge o máximo acúmulo de massa seca durante o enchimento de grãos dependem das condições edafoclimáticas em que a cultura está se desenvolvendo, as quais interferem no balanço entre fonte e dreno. Durante a primeira metade do enchimento de grãos, quando a atividade fotossintética é alta e a capacidade
P30F53YH (A)

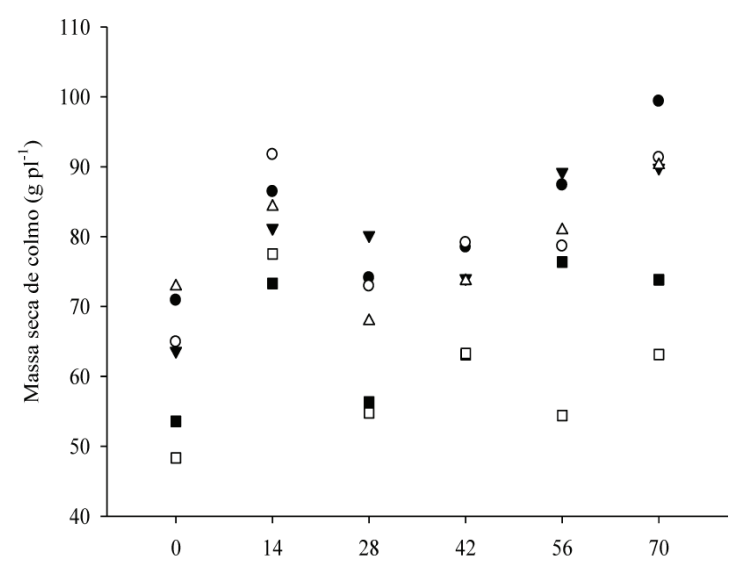

P30F53YH (C)

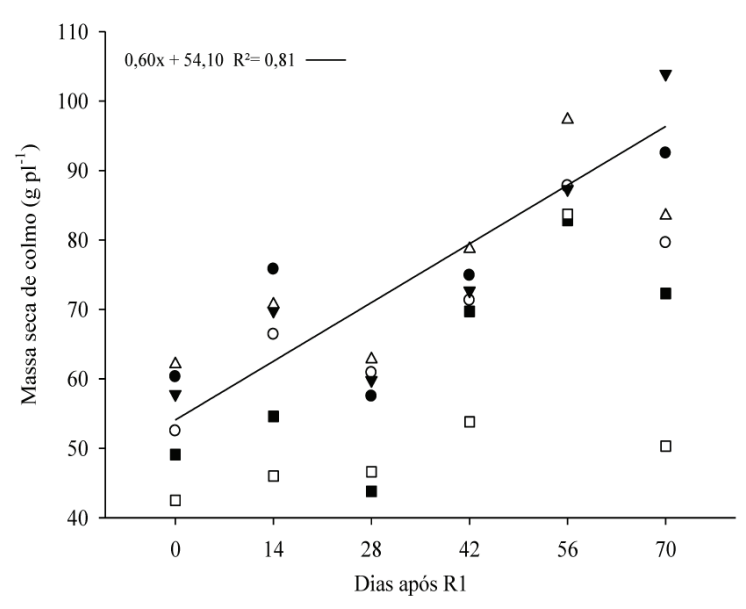

P1680YH (B)

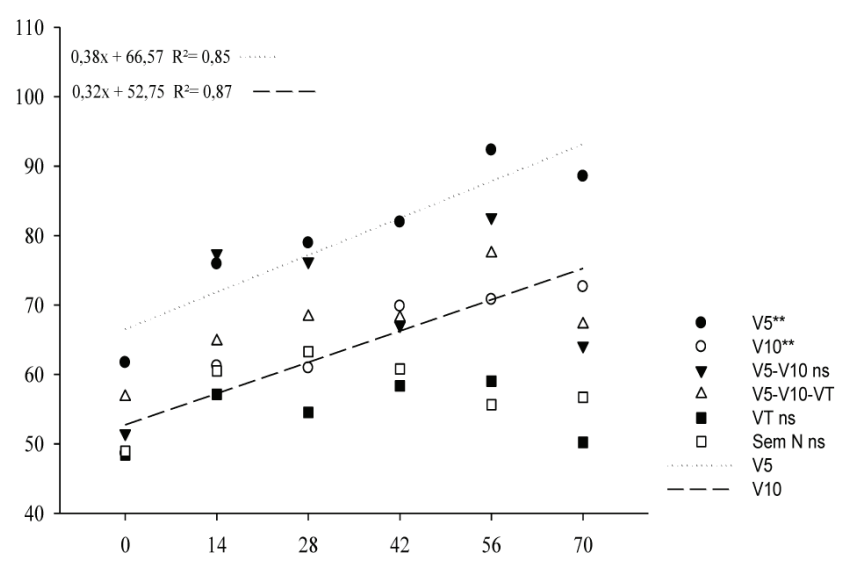

P1680YH (D)

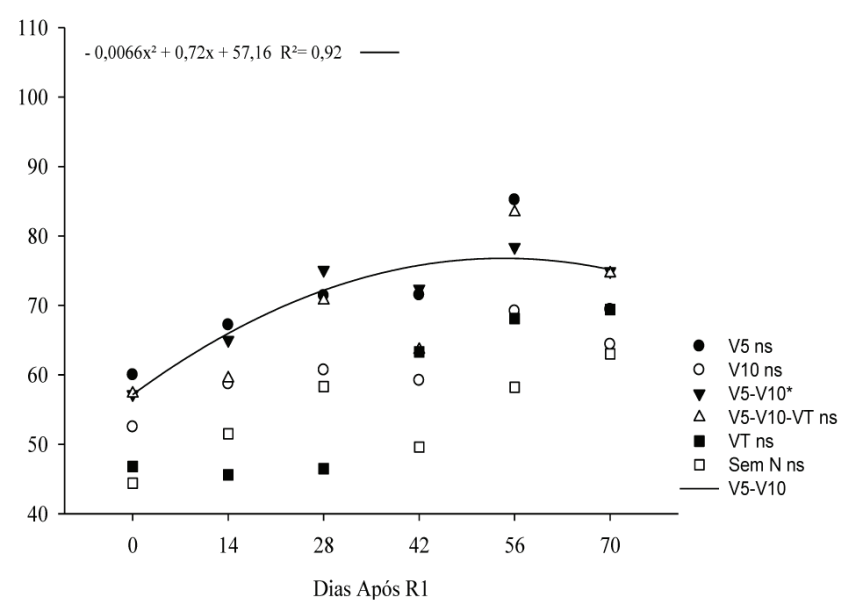

Figura 1. Acúmulo de massa seca no colmo após o espigamento $(\mathrm{R} 1)$ de dois híbridos de milho em função do estádio de aplicação de nitrogênio em cobertura. Lages-SC, 2014/2015 (A e B) e 2015/2016 (C e D). 
dos grãos de acumular açúcar é baixa, o colmo atua como dreno dos fotoassimilados produzidos pelas folhas, aumentando sua massa (Haegele et al., 2013).

Na segunda metade do enchimento de grãos, quando a atividade fotossintética das folhas diminui e a demanda dos grãos por açúcares aumenta, o colmo atua como fonte, remobilizando reservas para os grãos e reduzindo a sua massa. Esta tendência se acentua quando há restrições de fertilidade e altas densidades de plantas que abreviem a vida útil das folhas (Leolato et al., 2017). A ausência de um decréscimo significativo de fitomassa do colmo nas últimas amostragens é um indicativo de que a atividade fotossintética das folhas foi suficiente para atender à demanda dos grãos até a sua maturação fisiológica, não havendo necessidade de translocação acentuada de açúcares do colmo para o principal dreno da planta no final do ciclo da cultura. Outro ponto importante a destacar é que durante os dois anos de condução do experimento a massa seca do colmo apresentou alta variação entre os valores durante as coletas realizadas após R1. Isto também contribuiu para o pequeno número de regressões significativas entre os estádios de aplicação do nitrogênio.

O comportamento da massa seca nas folhas durante o enchimento de grãos nos diferentes estádios de aplicação de nitrogênio no milho na safra 2014/15 seguiu o modelo de regressão quadrático (Figura 2). O híbrido P30F53YH apresentou significância para os estádios em que o nitrogênio foi aplicado em uma única dose em V5 e parcelado em 1/3 V5 + 1/3 V10 $+1 / 3$ VT (Figura 2A). De acordo com as equações ajustadas aos dados, obteve-se um ponto de inflexão aos 23 dias para o estádio V5 e de 16 dias para o estádio $1 / 3 \mathrm{~V} 5+1 / 3 \mathrm{~V} 10+1 / 3 \mathrm{VT}$. Isto indica que a aplicação de nitrogênio toda em V5 manteve massa seca das folhas por um período maior durante a fase reprodutiva da cultura do milho do que o parcelamento em três vezes. Para o híbrido P1680YH, a regressão no modelo quadrático foi significativa em todos os estádios de aplicação do $\mathrm{N}$ em cobertura (Figura 2B). Quando o nitrogênio foi aplicado parceladamente em V5-V10, as plantas mantiveram o incremento da massa seca de folhas após o estádio R1 por um período de 21 dias, representando o maior período de incremento da massa foliar após o espigamento entre os tratamentos.

Na safra 2015/2016, a regressão no modelo quadrático foi significativa para todos os tratamentos utilizados no trabalho para a variável acúmulo de massa seca nas folhas (Figura 2C e 2D). Para os dois híbridos, o maior período de incremento da massa seca foliar durante o enchimento de grãos ocorreu quando o nitrogênio foi todo aplicado no estádio VT. Os pontos de máximo acúmulo com aplicação integral do N no pendoamento do P30F53YH e P1680YH foram atingidos aos 25 e 20 dias após R1, respectivamente. Neste tratamento, as plantas atingiram o florescimento com deficiência de nitrogênio. Após ser realizada a fertilização, a planta absorveu e iniciou o acúmulo de massa seca das folhas durante o período pós-florescimento. Isto é um indicativo da capacidade de absorção de $\mathrm{N}$ apresentada pelos híbridos modernos, característica que foi destacada por Kosgey et al. (2013), Bruin e Butzen (2014), Ning et al. (2014) e Ciampitti e Vyn (2013). Assim como no primeiro ano, a testemunha sem $\mathrm{N}$ apresentou menores valores de massa seca nas folhas em todas as épocas de amostragem.

Além dos menores valores, a testemunha sem $\mathrm{N}$ apresentou as maiores taxas de decréscimo da massa verde alocada às folhas à medida em que o enchimento de grãos evoluiu. Este comportamento era esperado, pois o nitrogênio é um constituinte essencial da 
clorofila. A não realização da cobertura nitrogenada diminui a formação da clorofila e aumenta sua degradação (Vargas et al., 2012). Estas duas características aceleraram a senescência foliar, resultando em menor massa seca de folhas verdes em todas as coletas.

O período compreendido entre o início de enchimento de grãos e a maturidade fisiológica da cultura é marcado pelo aumento na contribuição dos fotoassimilados presentes nas folhas para os grãos. As- sim, as folhas iniciam o processo da perda de massa seca após o espigamento. Mais de $63 \%$ do nitrogênio presente nas folhas pode ser remobilizado para outras partes da planta, principalmente para enchimento dos grãos (Debruin et al., 2013). A remobilização é intensificada a partir do florescimento e se estende até à maturidade fisiológica, diminuindo a massa seca das folhas acumulada durante o período vegetativo. Este comportamento foi encontrado por Borges
P30F53YH (A)

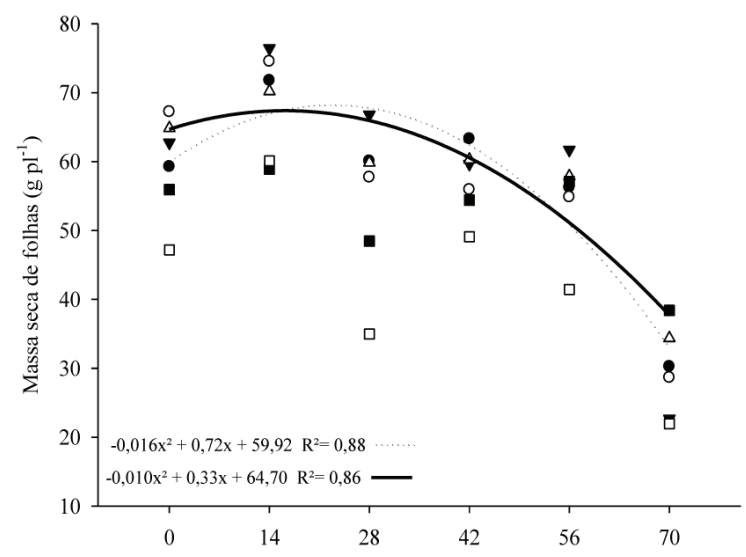

P30F53YH (C)

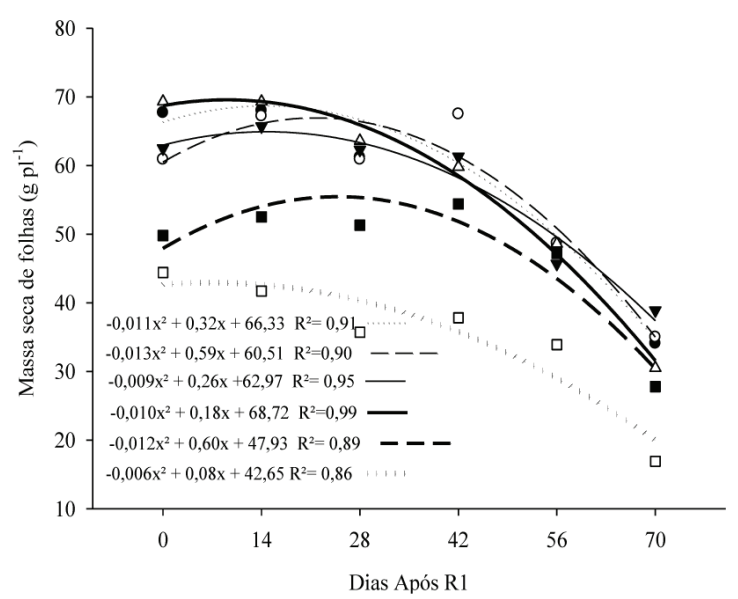

P1680YH (B)

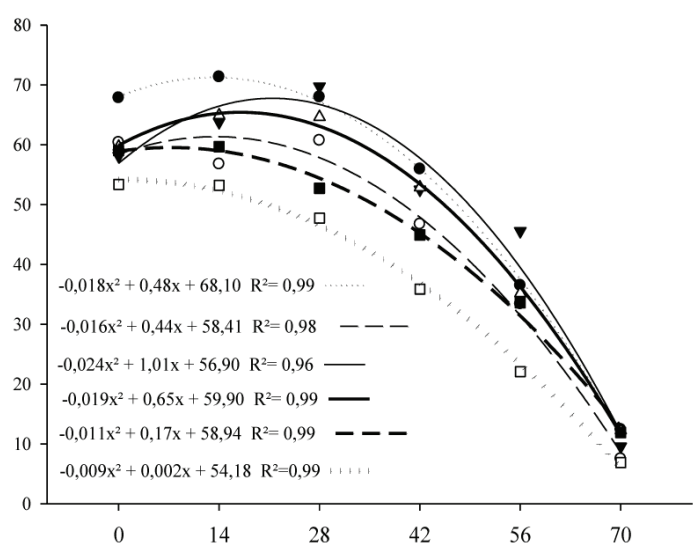

P1680YH (D)

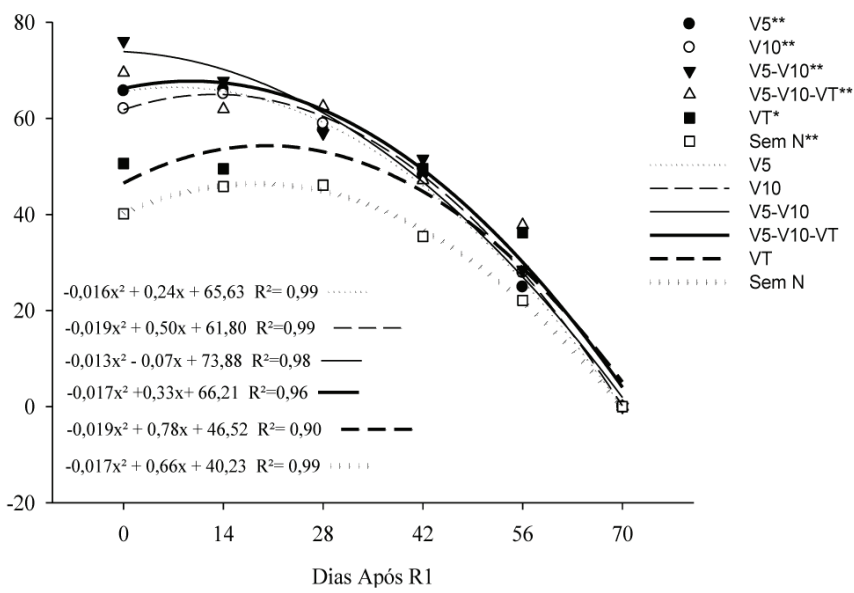

Figura 2. Acúmulo de massa seca nas folhas após o espigamento de dois híbridos de milho em função do estádio de aplicação de nitrogênio em cobertura. Lages-SC, 2014/2015 (A e B) e 2015/2016 (C e D). 
(2006), que, ao trabalhar com acúmulo de matéria seca em diferentes partes da planta de dois híbridos de milho, constatou que a massa incrementou até os 85 dias após a emergência, período que foi marcado pelo início do enchimento de grãos. Trabalhos realizados por Vasconcellos et al. (1983) e Karlen et al. (1988) evidenciaram a mesma tendência. Contudo, o máximo acúmulo da matéria seca nas folhas foi atingido próximo ao florescimento, mais cedo do que o encontrado no presente trabalho.

Um ponto importante a destacar é que não houve diferenças marcantes na massa seca das folhas entre os tratamentos com aplicação integral de $\mathrm{N}$ em V5 e V10 e aqueles em que a cobertura nitrogenada foi parcelada em duas (V5-V10) ou três (1/3 V5 + 1/3 $\mathrm{V} 10+1 / 3 \mathrm{VT})$ vezes. Isto é um indicativo de que o padrão de senescência foliar ao final do enchimento de grãos foi semelhante entre estes tratamentos, contrariando a hipótese do trabalho de que o maior parcelamento da cobertura nitrogenada retarda a senescência foliar durante o enchimento de grãos.

O acúmulo de massa seca nos grãos produzidos na safra 2014/2015 aumentou linearmente para todos os estádios que receberam nitrogênio, numa única dose ou parcelada, para os dois híbridos utilizados no experimento (Figura 3). As taxas de acúmulo de fitomassa nos grãos variaram de $1,54 \mathrm{a} 2,74 \mathrm{~g} \mathrm{dia}^{-1} \mathrm{e}$ 1,86 a 2,36 $\mathrm{g} \mathrm{dia}^{-1}$ para os híbridos P30F53YH (A) e 1680YH (B), respectivamente. Nos dois híbridos, as maiores taxas de acúmulo foram obtidas com a aplicação integral do $\mathrm{N}$ em V5.

O comportamento do acúmulo de massa seca nos grãos foi semelhante nas duas safras. Desta forma, em 2015/2016, o modelo de regressão linear apresentou significância para todos os estádios de aplicação de nitrogênio para os dois híbridos testados, independentemente do parcelamento ou não das fertilizações
(Figura 3C e 3D). De forma similar ao primeiro ano, as maiores taxas diárias de acúmulo de fitomassa nos grãos dos dois híbridos foram obtidas com a aplicação de todo o nitrogênio no estádio V5. Neste tratamento houve incrementos de 2,70 e 2,63 $\mathrm{g} \mathrm{dia}^{-1}$ após R1 para os híbridos P30F53YH e P1680YH, respectivamente. A testemunha apresentou o menor acúmulo de massa seca nos grãos do híbrido P30F53YH, incrementando esta variável em 1,60 $\mathrm{g} \mathrm{dia}^{-1}$ após R1. Já no híbrido P1680YH, o menor incremento foi registrado com a aplicação integral de nitrogênio em V10, que resultou no aumento da massa seca dos grãos de $2,32 \mathrm{~g} \mathrm{dia}^{-1}$.

Os resultados obtidos no trabalho corroboram com os encontrados por Borges (2006), em que a massa seca dos grãos apresentou incremento linear até a maturação fisiológica dos dois híbridos avaliados em seu trabalho. Resultados semelhantes foram encontrados por Ciampitti e Vyn (2011), em trabalhos realizados nos Estados Unidos.

A Figura 3 mostrou que, embora tenham ocorrido diferenças numéricas nos coeficientes angulares das retas nos tratamentos com N, estas diferenças foram pequenas, variando de 2,31 a 2,74 $\mathrm{g} \mathrm{dia}^{-1}$ para o híbrido P30F53 YH (Figura 3A e 3C) e de 1,86 a 2,63 g dia ${ }^{-1}$ para o P1680YH (Figura 3B e 3D). Nos dois anos agrícolas, os maiores valores foram registrados com a aplicação integral do $\mathrm{N}$ em V5. Isto indica que o fracionamento da fertilização nitrogenada em duas ou três vezes não trouxe vantagens significativas ao enchimento dos grãos, em relação à aplicação integral do fertilizante quando a planta tinha cinco folhas expandidas.

O comportamento da área foliar das plantas de milho nos diferentes estádios de aplicação de nitrogênio no milho na safra 2014/2015 seguiu o modelo de regressão quadrático para os dois híbridos testados no trabalho (Figura 4). A variável foi significativa em 
todos os estádios que receberam as fertilizações, independentemente de ocorrer o parcelamento ou não. A aplicação de todo o nitrogênio no estádio V10 fez o híbrido P30F53YH expressar o maior tempo de incremento na área foliar entre os tratamentos, atingindo o valor máximo 18 dias após R1 (Figura 4A). Já a aplicação parcelada em 1/3 V5 + 1/3 V10 + 1/3 VT proporcionou o menor tempo de aumento na área foliar, com o máximo ocorrendo 1,5 dia após o espigamen- to. Isto indica que a aplicação de uma parte do nitrogênio no pendoamento não foi eficaz em aumentar a durabilidade da área foliar para o híbrido P30F53YH.

A aplicação de todo o nitrogênio em VT proporcionou ao híbrido P1680YH o maior tempo de permanência da área foliar, atingindo o ponto de máxima aos 20 dias após R1 (Figura 4B). Isto evidencia que híbridos mais precoces podem absorver nitrogênio tardiamente e manter a área foliar por um perío-
P30F53YH (A)

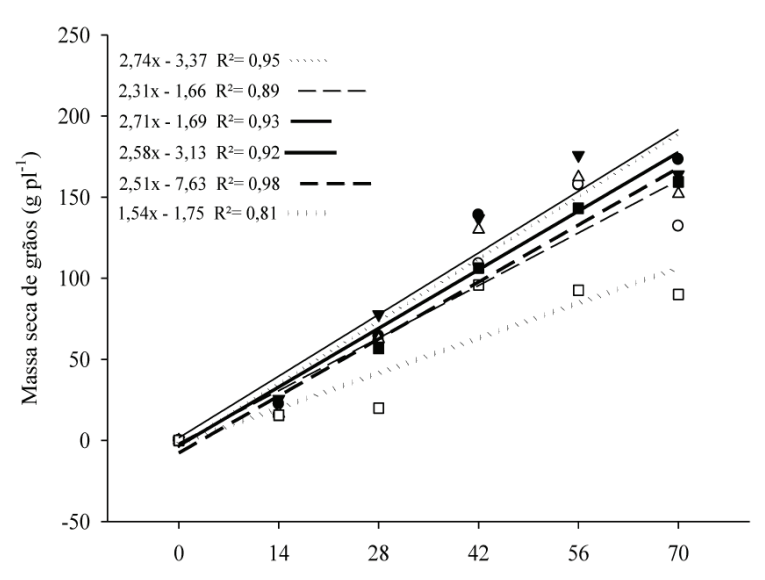

P30F53YH (C)

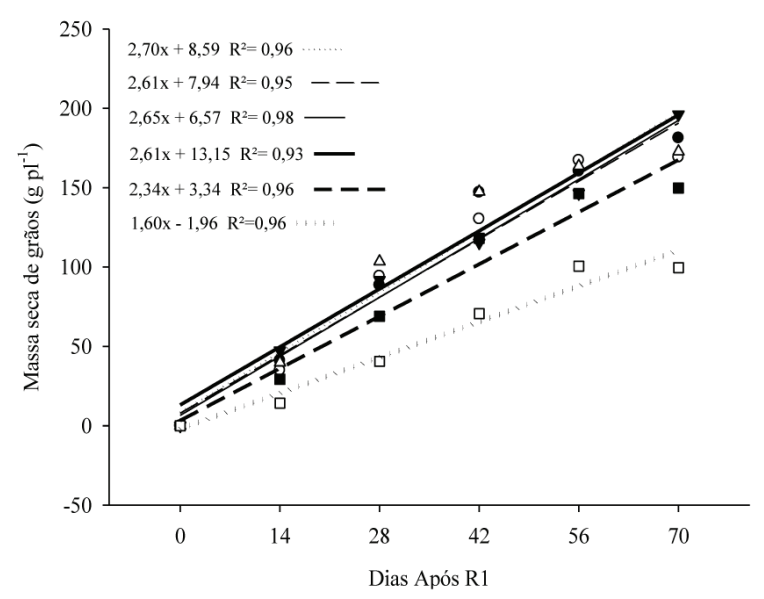

P1680YH (B)

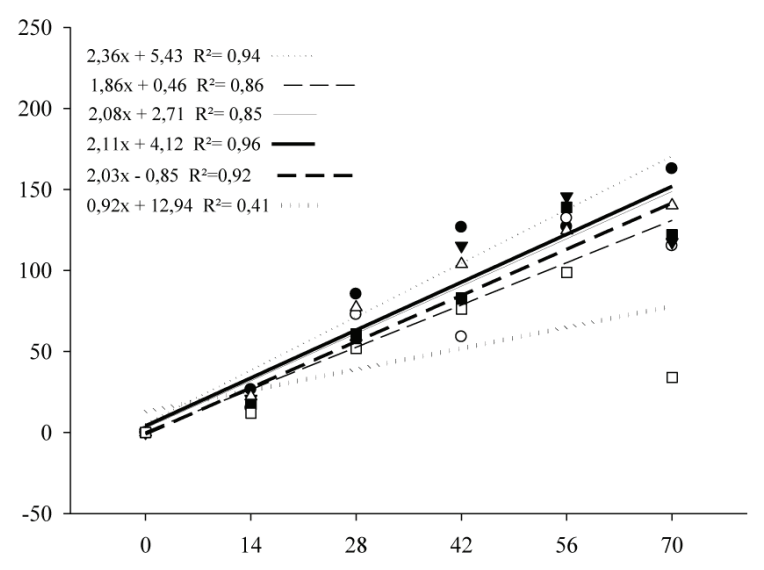

P1680YH (D)

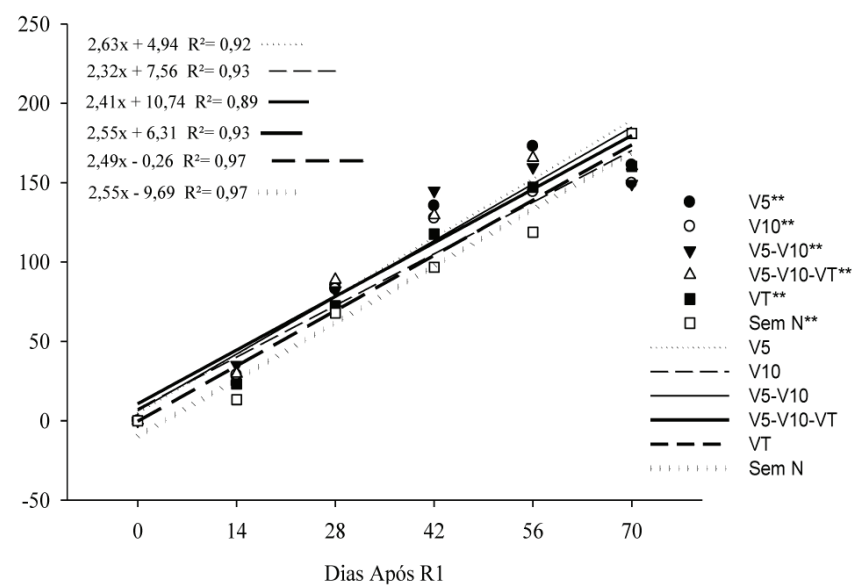

Figura 3. Acúmulo de massa seca nos grãos após o espigamento (R1) de dois híbridos de milho em função do estádio de aplicação de nitrogênio em cobertura. Lages-SC, 2014/2015 (A e B) e 2015/2016 (C e D). 
do maior, proporcionando condições para melhorar o enchimento de grãos. A testemunha evidenciou o menor tempo de incremento na área foliar, atingindo seu máximo aos dois dias após R1.

Na safra 2015/16, a área foliar seguiu o mesmo comportamento da safra 2014/15, onde o modelo de regressão quadrático apresentou significância para todos os estádios em que receberam as fertilizações, independentemente de ser aplicado em uma única vez ou de forma parcelada (Figura 4C e 4D). O híbrido P30F53YH externou a maior tempo de área foliar com a aplicação de nitrogênio parcela em V5-V10, atingido o máximo aos 15 dias após R1. Já o híbrido P1680YH apresentou essa característica para a aplicação de todo nitrogênio em VT, com máxima área foliar aos 17 dias decorridos após R1. A testemunha
P30F53YH (A)

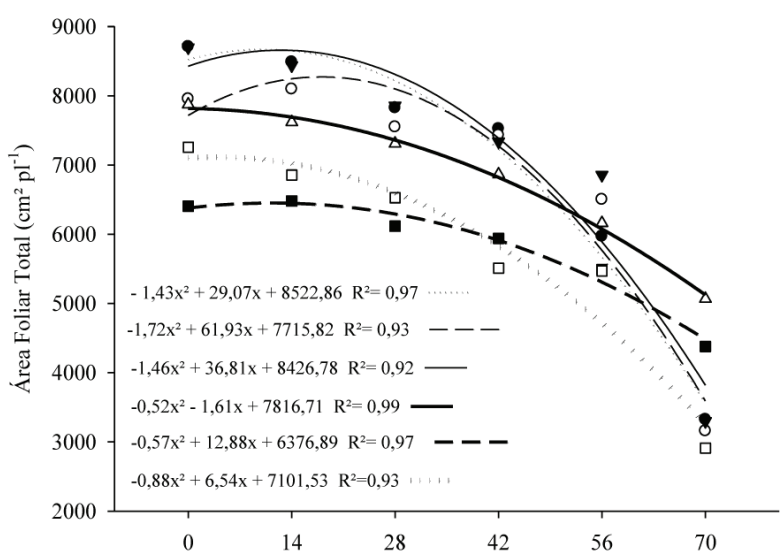

P30F53YH (C)

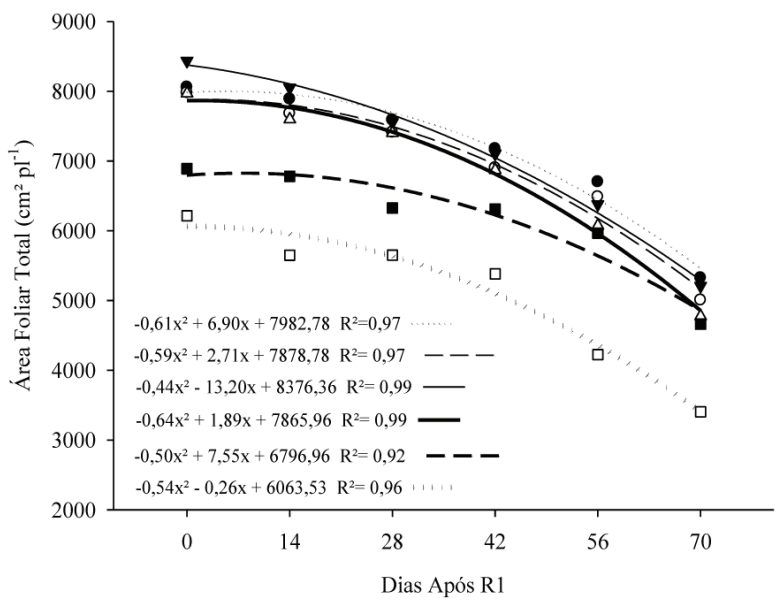

P1680YH (B)

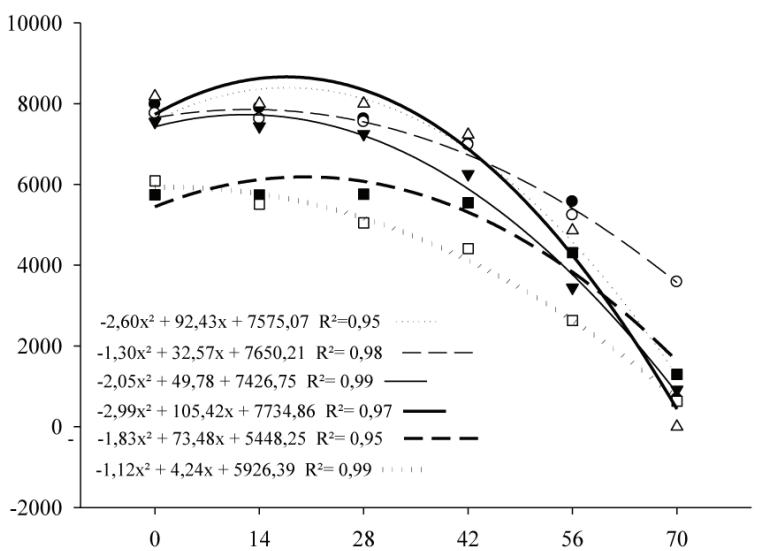

P1680YH (D)

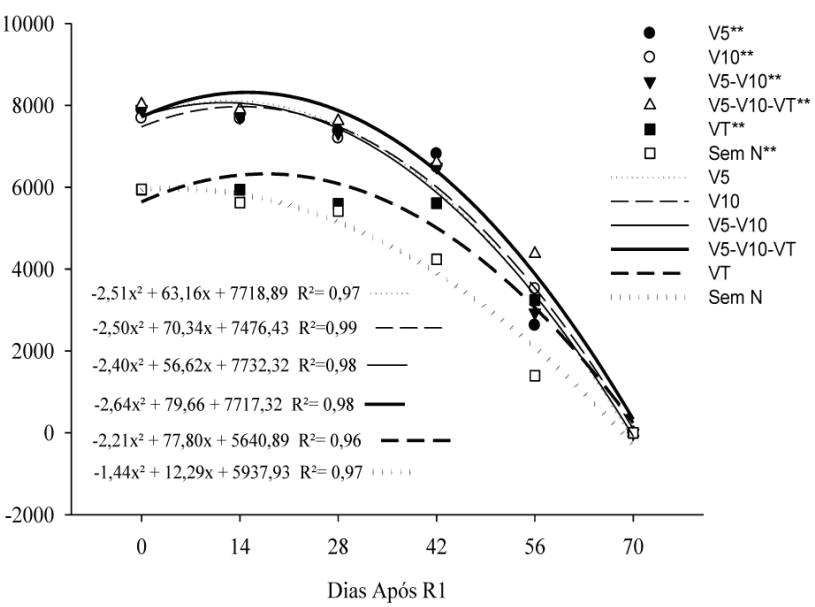

Figura 4. Área Foliar após o espigamento (R1) de dois híbridos de milho em função do estádio de aplicação de nitrogênio em cobertura. Lages-SC, 2014/2015 (A e B) e 2015/2016 (C e D). 
apresentou o menor tempo de incremento na área foliar para os dois híbridos testados.

A eficiência de absorção do nitrogênio pelas raizes após o período de florescimento é um fator importante, pois ela minimiza a remobilização do nitrogênio dos orgãos vegetativos e reprodutivos, mantendo a área foliar por maior tempo e prolongando o acúmulo de massa seca (Kosgey et al., 2013). A continuidade da absorção de nitrogênio pelas raízes durante o período de enchimento de grãos reduz a senescência de folhas, aumentando a duração da fotossíntese e, consequentemente, o rendimento de grãos (Ciampitti \& Vyn, 2011). Neste contexto, a expectativa teórica do trabalho era de que o maior fracionamento da adubação nitrogenada de cobertura, com aplicação de $1 / 3$ da dose total no pendoamento, prolongasse a duração da área foliar, retardando a senescência foliar e aumentando o acúmulo de massa seca nos grãos. Esta expectativa não foi confirmada pelos dados apresentados nas Figuras 3 e 4.

As recomendações de adubação (N-P-K) realizadas para o experimento objetivaram alcançar tetos de rendimento de grãos equivalentes a $21 \mathrm{t} \mathrm{ha}^{-1}$. Contudo, as produtividades atingidas nas duas safras agrícolas não ultrapassaram 15,5 t ha- em nenhum dos tratamentos (dados não mostrados). Quanto mais alto o teto produtivo do milho maior é a demanda da cultura por nitrogênio e a possibilidade de resposta ao fracionamento da cobertura nitrogenada (Fontoura \& Bayer, 2009). A quantidade de nitrogênio aplicada (30 kg de $\mathrm{N} \mathrm{ha}^{-1}$ na semeadura $+300 \mathrm{~kg}$ de $\mathrm{N} \mathrm{ha}^{-1}$ em cobertura), associada ao teor elevado de matéria orgânica do Nitossolo em que se conduziu o trabalho $\left(52 \mathrm{~g} \mathrm{~kg}^{-1}\right)$, pode ter fornecido um excesso de nitrogênio, em relação à demanda dos grãos pelo nutriente. A ausência de um decréscimo consistente na massa seca alocada aos colmos nas amostragens realizadas aos 55 e 70 dias após o espigamento reforça esta hipótese. Tais fatos podem ter contribuído para limitar as vantagens agronômicas do parcelamento da adubação nitrogenada em cobertura em três estádios fenológicos, nas condições edafoclimáticas em que o ensaio foi conduzido.

\section{Conclusões}

O parcelamento da fertilização nitrogenada em três vezes até o pendoamento não aumentou a área foliar e a massa seca alocada às folhas durante o enchimento de grãos, em relação a aplicação integral de $\mathrm{N}$ em V5 e V10.

A aplicação de 1/3 da dose de N em V5, V10 e VT não aumentou as taxas de acúmulo de massa seca nos grãos e nem os valores de massa concentrada nos grãos durante o enchimento, em relação aos tratamentos com aplicação integral do N em V5 ou V10.

\section{Agradecimentos}

Ao CNPq pela concessão da Bolsa de Produtividade em Pesquisa ao primeiro autor do trabalho. À Capes pela concessão de bolsa de estudos ao segundo e terceiro autores do trabalho. À FAPESC/PAP/ UDESC pelo apoio financeiro à execução do trabalho.

\section{Referências}

ARGENTA, G.; SANGOI, L.; SILVA, P. R. F.; RAMPAZZO, C.; GRACIETTI, L. C.; STRIEDER, M. L.; FORSTHOFER, E. L.; SUHRE, E. Potencial de rendimento de grãos de milho em dois ambientes e cinco sistemas de produção. Scientia Agraria, Curitiba, v. 4, n. 1, p. 27-34, 2003.

DOI: $10.5380 /$ rsa.v4i1.1062. 
BORGES, I. D. Marcha de absorção de nutrientes e acúmulo de matéria em cultivares de milho. 2006. 115 p. Tese (Doutorado em Fitotecnia) - Universidade Federal de Lavras, Lavras, 2006.

BORRÁS, L.; MADDONI, G.; OTEGUI, M. E. Leaf senescence in maize hybrids: plant population, row spacing and kernel set effects. Field Crops Research, Amsterdam, v. 82 , n. 1, p. 13-26, 2003.

DOI: 10.1016/S0378-4290(03)00002-9.

BRUIN, J.; BUTZEN, S. Nitrogen uptake in corn. Crop Insights, v. 24, n. 4, p. 1-8, 2014.

CIAMPITTI, I. A.; VYN, T. J. A comprehensive study of plant density consequences on nitrogen uptake dynamics of maize plants from vegetative to reproductive stages. Field Crops Research, Amsterdam, v. 121, p. 2-18, 2011. DOI: $10.1016 /$ j.fcr.2010.10.009.

CIAMPITTI, I. A.; VYN, T. J. Grain nitrogen source changes over time in maize: a review. Crop Science, Madison, v. 53. p. 366-377, 2013.

DOI: $10.2135 /$ cropsci2012.07.0439.

COMISSÃO DE QUIIMICA E FERTILIDADE DO SOLO, RS/SC. Recomendações de adubação e calagem para os Estados do Rio Grande do Sul e Santa Catarina. 10. ed. Passo Fundo: Sociedade Brasileira de Ciência do Solo, 2004. 394 p.

DEBRUIN, J.; MESSINA, C. D.; MUNARO, E.; THOMPSON, K.; COMLON-BECKNER, C.; FALLIS, L.; SEVENICH, D. M.; GUPTA, R.; DHUGGA, K. S. $\mathrm{N}$ distribution in maize plant as a marker for grain yield and limits on its remobilization after flowering. Plant Breeding, Berlin, v. 132, n. 5, p. 500-505, 2013. DOI: $10.1111 /$ pbr.12051.

DUVICK, D. N. Genetic progress in yield of United States maize. Maydica, Bergamo, v. 50, n. 3, p. 193-202, 2005.

ECHARTE, L.; ROTHSTEIN, S.; TOLLENAAR, M. The response of leaf photosynthesis and dry matter accumulation to nitrogen supply in an older and a newer maize hybrid. Crop Science, Madison, v. 48, p. 656-665, 2008. DOI: 10.2135/cropsci2007.06.0366.

FONTOURA, S. M. V.; BAYER, C. Adubação nitrogenada para alto rendimento de milho em plantio direto na região centro-sul do Paraná. Revista Brasileira de Ciência do Solo, Viçosa, MG, v. 33, p. 1721-1732, 2009.

DOI: 10.1590/S0100-06832009000600021.

HAEGELE, J. W.; COOK, K. A.; NICHOLS, D. M.; BELOW, F. E. Changes in nitrogen use traits associated with genetic improvement for grain yield of maize hybrids released in different decades. Crop Science, Madison, v. 53, p. 1256-1268, 2013. DOI: 10.2135/cropsci2012.07.0429.

KARLEN, D. L.; FLANNERY, R. L.; SADLER, E. J. Aerial accumulation and partitioning of nutrientes by corn. Agronomy Journal, Madison, v. 80, p. 232-242, 1988. DOI: 10.2134/agronj1988.00021962008000020018x.

KOSGEY, J. R.; MOOT, D. J.; FLETCHER, A. L.; MCKENZIE, B. A. Dry matter accumulation and postsilking $\mathrm{N}$ economy of stay green maize (Zea mays L.) hybrids. European Journal of Agronomy, v. 51, p. 43-52, 2013. DOI: 10.1016/j.eja.2013.07.001.

LEOLATO, L. S.; SANGOI, L.; DURLI, M. M.; PANISON, F.; VOSS, R. Growth regulator and maize response to the increase in plant density. Pesquisa Agropecuária Brasileira, Brasília, DF, v. 52, n. 11, p. 997-1005, 2017. DOI: $10.1590 / \mathrm{s} 0100-204 \times 2017001100005$.

NING, P.; LI, S.; LI, X.; LI, C. New maize hybrids had larger and deeper post-silking roots than old ones. Field Crops Research, Amsterdam, v. 166, p. 66-71, 2014. DOI: 10.1016/j.fcr.2014.06.009.

RITCHIE, S. W.; HANWAY, J. J.; BENSON, G. O. How a corn plant develops. Ames: Iowa State University of Science and Technology, 1993. (Special Report, 48).

SANGOI, L.; SILVA, P. R. F.; PAGLIARINI, N. H. F. Estratégias de manejo da adubação nitrogenada em milho na região sul do Brasil. Lages: Graphel, 2016. $122 \mathrm{p}$. 
SANGOI, L.; ZANIN, C. G.; SCHIMITT, A.; VIEIRA, J. Senescência foliar e resposta de híbridos de milho cultivados em diferentes épocas ao adensamento. Revista Brasileira de Milho e Sorgo, Sete Lagoas, v. 12, n. 1, p. 21-32, 2013.

DOI: 10.18512/1980-6477/rbms.v12n1p21-32.

TOLLENAAR, M.; LEE, E. Yield potential, yield stability and stress tolerance in maize. Field Crops Research, Amsterdan, v. 75, n. 3, p. 161-169, 2002.

DOI: $10.1016 / \mathrm{S} 0378-4290(02) 00024-2$.
VARGAS, V. P.; SANGOI, L.; ERNANI, P. R.; SIEGA, E.; CARNIEL, G.; FERREIRA, M. A. Os atributos das folhas são mais eficientes do que o $\mathrm{N}$ mineral no solo para avaliar a disponibilidade deste nutriente para o milho. Bragantia, Campinas, v. 71, n. 2, p. 21-31, 2012.

DOI: $10.1590 / \mathrm{S} 0006-87052012000200014$.

VASCONCELlOS, C. A.; BARBOSA, J. V.; SANTOS, H. L.; FRANÇA, G. E. Acumulação de massa seca e de nutrientes por dois híbridos de milho com e sem irrigação suplementar. Pesquisa Agropecuária Brasileira, Brasília, DF, v. 18, n. 8, p. 887-901, 1983. 